\title{
Health Care Practices of Older People in Sylhet: A Study Conducted in Slum Areas of Sylhet City of Bangladesh
}

\author{
Jiban Kumar Pal \\ MSS (Thesis) Student, Department of Social Work \\ Shahjalal University of Science \& Technology \\ (SUST), Sylhet-3114, Bangladesh \\ jibanpal42@gmail.com
}

\author{
Muhammed Muazzam Hussain \\ Professor, Department of Social Work \\ Shahjalal University of Science \& Technology \\ (SUST), Sylhet-3114, Bangladesh \\ muazzam777@yahoo.com
}

\begin{abstract}
The present study was undertaken to determine the health care practices of older people in slum areas and to find out their actual health situation, treatment experiences, health seeking behavior, mental situation and their valuable suggestion for improving their present conditions. The present study was qualitative in nature. It was carried out on six slums under the three wards of Sylhet City Corporation area. The data for the study was collected from 20 people and two focus group discussion with eight older people in each group having age 60 years and above and living in slum areas in Sylhet City Corporation. Purposive sampling technique was employed for selecting sample from the older people who live in the selected six slums. In the slum areas older people mostly suffer from headache, skin diseases, cough and cold, gastric ulcer, toothache, diarrhea, heart disease, hypertension, cancer, asthma, urinary, TB, depression, mental stress, feelings of insecurity. Generally the slum older people take treatment from M.A.G. Osmani Medical College Hospital and Ragib-Rabeya Hospital Sylhet. Negligence, poverty, prejudice allows the slums older people to be kept aloof from availing modern medical care. So, slum older people go to homyopathitic doctor, quack doctor or kabiraj for treatment due to cheaper cost. Lack of proper information and awareness and bad experiences in government hospitals, many extremely poor slum older people first sought treatment from cheaper or free traditional healers (kabiraj), from other religious people or religious places such as a maazar. In slum areas older people lead a troublesome life due to insufficient income or allowances from state.
\end{abstract}

Keywords: Older People, Slum Areas, Sylhet City, Health Care, Health Seeking Behavior

\section{INTRODUCTION}

Bangladesh is passing through technological, social, cultural and demographic transition. Consequently increase in awareness of health care among the people took place, which led to the improvement in the quality of health care facility. The older people are one of the most vulnerable and high-risk groups in terms of health and socio-economic status in the society today. The family support system and more specifically the strong emphasis on one's obligation to older people that has worked for hundreds of years in Bangladesh. In traditional societies, older people are treated as resources and are respected by all and enjoyed a valued social position in the extended households. But this situation is changing enormously due to the breakdown of traditional family pattern, changes in traditional norms and values, innovation of modern medical facilities and increasing the rate of older people. For these changes, the older people face difficulty to meet their physiological, psychological and social needs. They are mostly vulnerable in terms of living arrangement, food consumption and possessions on wealth, participation in decision making of the family and social attitude and values. A lot of multi-casual factors are responsible for the current situation of the older people in slum areas in Bangladesh [1]. In Bangladeshi context because of traditional norms and religious and social values most of the older people are living with their offspring but at the same time it should be elicited that how easier this co-residency. Because of wide spread poverty and socio-economic change, living together is no guarantee of economic well-being of the older people [2].

Health status of the older people is a major concern in Bangladesh. Bangladesh lacks medical facilities and infrastructure to meet the needs of the vast slum population not to speak of the older population. Older population expressed concern about their health as it has a direct impact on their ability to earn for their livelihood. Health care is one of the basic needs for the survival of the older people in Bangladesh. The majority of older people in Bangladesh live in absolute poverty [3]. Older 
people suffer from cumulative effects of a lifetime of deprivation, entering old age in a poor state of health, and without savings or material assets. In the urban and rural areas majority of the elderly population suffered from weakness $(75 \%$ and $75 \%$ ) followed by eye sight (95\% and 65\%), sleeping problem (45\% and $45 \%)$, Blood pressure (40\% and $25 \%$ ) body pain (80\% and $45 \%)$ and pin in joint $(95 \%$ and $35 \%)$. in rural areas more older population suffers from eyesight, hearing and denture, weakness, sleepless, mobility, blood pressure, stiff joint, constipation, pain in join in back rheumatic [4]. A rapid increase in the number of the older people as well as their proportion in our population, has led us to being more conscious of the many social, economical, psychological and health problems of the older people in our country. Of these problems, health and medical problems are generally considered to be important as they affect a large majority of the older people [5]. It is very important to understand the health needs of the older people and so solicit their opinion in improving the existing health care system in the country. Therefore, this study was undertaken to understand the health care practices of older people and to gather some information about their perceive health needs using the information and over of Sylhet City.

\section{OBJECTIVES OF THE STUDY}

The overall objective of the study was to learn about the health care practices of older people in the slum areas of Sylhet City as well as to identify how the cultural patterns of slum areas affect the care of the older people. Therefore, the specific objectives were selected:

- To know the general health condition of older people living in the slum areas of Sylhet City.

- To know their current health care and hygiene practices.

- To get a better understanding about their health seeking behavior and treatment patterns.

- To identify the problems and challenges they face in getting health care services.

- To present some suggestion and recommendations to improve their health conditions.

\section{CONCEPTS AND DEFINITION}

For the purposes of the study, the following operational definitions of the key terms were used. Old age is considered the closing period of human life of an individual. The Constitution of Bangladesh in its clause 15(d) clearly declares to introduce the Social Security Programme in 1998 for the older people who is 65 years or above for man and 62 years or above for woman [6]. The government, through the Public Servants (Retirement) (Second Amendments) Ordinance, 2012, promulgated on Dec 6, 2012, increased the retirement age of the public servants to 59 years from 57 years and the freedom fighter public servant will enjoy one more year in job before going on retirement [7]. Therefore the inclusive criteria were to become Bangladeshi citizens living in the slum areas in Sylhet City and having the age of sixty years and above. In Sylhet City Corporation areas slums are known as colony. In this study slum (Colony) refers to a place where poor people live with poverty, poor healths and nutritions, densely, inadequate lighting, lack of safe drinking water, water logging during rains, absence of toilet facilities and non-availability of basic physical and social services for older people and their health care practices. Health care is generally used to indicate the diagnosis, treatment, and prevention of disease, illness, injury, and other physical and mental impairments in humans. In this study health care was used to refer to the government health care services, NGO, voluntary and family health care related services etc. In this study Sylhet city was used to refer the administrative area of Sylhet City Corporation including the 27 wards. Health seeking behavior was used to refer the way of seeking health care and their attitudes about health care.

\section{Methodology of The Study}

This study was based on qualitative research method with various data collection procedures, such as interview, focus group discussion (FGD) were employed to collect necessary information. Although the study was based on primary data, a number of secondary sources, such as policy documents, journal articles, academic books, official documents were used to conduct the study. In this study Sylhet city was used to refer Sylhet City Corporation. The total numbers of slums in Sylhet City Corporation are about 754. Six slums among three words (07, 08, and 09) of Sylhet City Corporation were selected purposively for collecting the relevant information about health care practices of older people. Among the words and slums of the study area as representative sample were selected purposively. The slums in Sylhet City are known as colony and the name of the colonies used here 
Safiq Khan's Colony, Fajil Chisti, Kotwali, Payara Mia's Colony, Pir Mahallah, Kotwali, Sudangsho Babu's Colony, Hawladar Para, Faruk Mia's Colony, Korar Para, Hannan Mia's Colony, Akhalia, Sastu Mia's Colony, Akhalia. These slums were selected for conducting study on older people and their health care practices because these areas were known to the researcher. The primary population of the study was comprised the aggregate number of older people living in slums areas of Sylhet City who belong to the age of sixty and above. The total older population of the above six slums were 89 and among them 53 female and 36 male person. Purposive sampling method was used to access the data necessary to address the research objectives. A number of 20 samples were purposively selected and collected information from each of them. In addition two focus group (FG) were formed with eight participants in each group. The methods/techniques of data collection were semi-structured interview schedule and focus group discussion (FGD). Apart from primary sources of data secondary source was used in order to understand the present situation of older people in slum areas. I

\section{VALIDITY AND RELIABILITY OF DATA}

Validity in research is concerned with the accuracy and truthfulness of scientific findings [8]. In this study, it was demonstrated what actually exists and a valid instrument or measure actually measured and what it was supposed to measure. Reliability is concerned with the consistency stability and repeatability of the informant's accounts as well as the investigators' ability to collect and record information accurately [9]. In this study the consistently of the same results over repeated testing periods was checked. During study period, the researcher using the same or comparable methods obtained the same or comparable results every time and used the methods on the same or comparable subjects. The researcher developed consistent responses or habit. The researcher collected information from the respondents through in-depth interview and focus group discussion and observed their present health conditions personally. Whenever needed, responses were cross-checked with the respondents over telephone. In case of content analysis, principle of authenticity and subjectivity was maintained. So data were credible and reliable as possible.

\section{Data Analysis}

Qualitative analysis of data requires an interpretive approach concerned with understanding the meaning which people attach to phenomena (actions, decisions, beliefs, values, etc.) within their social world [10]. The recorded interviews and focus group discussions were transcribed in full and the accuracy was checked against the original recording and noted by the researcher. The transcripts were analyzed using thematic analysis, derived deductively from the research questions and inductively from meanings or actual phrases used by the participants. The trustworthiness of the data analysis process was enhanced by the researcher. Triangulation of data was ensured by comparing focus group discussions and interviews data for identifying consistency and contradictions and eventually inconsistencies were examined and interpreted. In contrast, semi-structured interviews provided a great deal of information concerning personal issues. Interview and focus group discussion participants talked about their health status, hospital experiences and the issues of general wellbeing. They were confident to talk about family matters including personal experiences of care, evaluation of self, and attitude towards diseases, treatment and future planning.

\section{ETHICAL ISSUES OF THE STUDY}

This is particularly important issue in qualitative research where there is significant potential for misleading people to be genuinely interested, using contacts to gain confidential information, betraying confidences, and consequentiality. Participation in the study was voluntary and relied on the ethical principal of consent. At the start of interview and focus group discussion, the study purpose and nature were explained. Although the written consent was not taken from the respondent but verbal consent was taken from them. Since the most of the participants were illiterate in Bengali and English; their presence at the interview or focus group was deemed to be consent. It was further explained that while the anonymity of individual participants were preserved that their verbatim may be published, although action was taken to prevent them being identified.

\section{Limitations OF THE STUDY}

The study was carried out on health care practices of older people at slum areas in Sylhet City Corporation to investigate the present health situation and care practices. The data for the study was collected from 20 people having age 60 pulse and living in slums in Sylhet City Corporation area and using purposive sampling technique and semi-structure interview schedule during the month January 
to April 2015. Only two focus group discussion consisting with eight older people in each group in slum areas and their family care givers. As a qualitative study the sample size was small and that could not present the whole older people in slum areas in Sylhet City Corporation. The findings are not generalizable beyond the study sample.

\section{FINDINGS OF THE STUDY}

\subsection{Demographic Status of the Respondents}

Age is important to gather demographic information of the population living in the studied area to understand the demographic characteristics of older people in the slums area. As the participant were aged sixty years and above and it is seen the average age of respondents in slum areas in Sylhet City Corporation is 70.25. In the slum areas most of the older people live with their son's family. So, the family size is large because they live with sons and grandsons. Maximum slum dwellers are out of education. However, NGOs and other organization try to bring them in informal education. Some respondents got educational facilities when he stayed in villages. It reveals from the collected information that only few respondents completed primary schooling and other dropped out due to poverty of their parents. Most of the older people are unemployed and they spend their time in home. Although a few numbers of older people do some work like running a shop and pull rickshaw. Their annual income is low but expenditure is high due to suffer various diseases. For their treatment and livelihood they depend on their offspring. Marital Status of the respondents was also revealed that thirty three percent of the respondents are widow and widower. The high proportion of widowhood among the older women and who live with their son or daughter's family. Loneliness is a major problem of the older people when they lose one marital partner. It also indicates that no one will remain in the household to provide support and care to the half to the older people.

\subsection{Diseases of the Respondents}

The study reveals that majority of the slum older people suffer from one or more diseases. In the slum areas older people mostly suffer from the following diseases, headache, skin diseases, gastric/ ulcer, toothache, diarrhea and dysentery, heart disease, diabetes mellitus, hypertension, cancer, asthma, urinary, TB, depression, mental stress, feelings of insecurity in their daily life. One 74 years male interview participant shared his view about frequently suffer primary hypertension,

"In my life I suffer hypertension frequently due to my old age and tension for my wife who suffers cancer long time. Ifeel headache, drowsiness, confusion, vision disorders and vomiting when I suffer hypertension".

Another 75 years old female interview participant said,

"I have hypertension about three years long and it creates many problems in my body. I don't know why it raises sometimes. Doctor said to me, if I don't reduce my tension then it will not reduce".

Hypertension results from a complex interaction of genes and environmental factors. Several environmental factors influence hypertension like lack of exercise, obesity, stress, and depression. One 62 years old female focus group discussion participant shared his opinion,

"I suffer blood pressure long time. My blood pressure is now normal but sometimes it raises high due to anxiety and depression. I feel stress all time for my own diseases and unable to earn something for daily medicine. Although I live with my elder son's family but lack of resources he cannot maintain his expenditure. These are the causes of my hypertension raising".

The study findings suggest that, the slum older people are facing troublesome situation for their heart problem. It is more cost for treatment and bypass surgery. One FG participant shared his view in the following way:

"I have heart problem from three years. Before nine months first time If felt heart attack and was admitted in Osmani Hospital. When I attacked this problem I felt moving my head and Ifall down the yard. From that attack I lost my one leg energy and cannot move now without the stick".

Another FG participant included,

"Last year my husband died for heart attack. Now I suffer from chest pain. I visited doctor for this and he said although it comes from gastric problem but I should aware for heart attack. It can occur any time and lose my life." 
The data demonstrate that the respondents suffer cancer diseases. One female participants who is 63 years suffers lung cancer eight months and said,

"I have lung cancer and it was found out before eight months. Now Ifeel serious illness for these diseases. I sufferfever, fatigue, weight loss, and persistent pain, skin diseases, bleeding in mouth, persistent cough and change in my voice".

The study data also describe that fifty five percent slum older people use tobacco and alcohol and due to this they face some cancer diseases. One interview 63 years older female participant said,

"Regularly I use tobacco (gul) in my mouth and it has affected my mouth and teeth. I feel pain due to infection in my mouth. Although I have gotten treatment from Kabiraj but it has not worked properly. Ten days ago I visited Osmani Hospital for treatment and doctorhas said I should take operation in my mouth and take medicine regularly".

One 78 years old FG participant included,

"About ten years I suffer asthma and it gives pain all time. I cannot take breath properly without inhaler and medicine. I know this disease has come from my father who had asthma. Another factor is dirty environment in our colony. In winter session I suffer much due to dust and cold wind. I went to hospital for treatment but said it will not be removed properly".

Asthma is a common disease in slum older people because the unhygienic environment and lack of awareness about health care. One male (71 years) participant included,

"I have healing problem (Saskosto) and it gives pain me all time. I can't walk long time due to breathe problem and I need to take rest after five minute. When winter season come then I face more problem for my asthma. Regularly I take medicine for minimizing this problem".

Another FG participant said about his asthma in the following way:

"I suffer asthma long time and I have taken treatment from Ragib-Rabeye Hospital but that did not work properly. Now I do not go to hospital but buy medicine from pharmacy in our bazaar. It is burden for me for doing any work".

The study findings suggest that diabetes is another disease for older people. One 73 years older female participant included,

"I suffer diabetes about seven years long and it causes my foot problem. I cannot take all food due to diabetes. My disease creates many problems in my eyes and two operation treatments to ok for this".

One participant narrated his health condition in the following way:

"My present health status is not so good because I suffer from various diseases like heart disease, dysentery, diarrhea, eye problem, loss of energy and some mental stress like tension for my health, anxiety and most of the time I feel loneliness".

Another 67 years old male FG participant shared his diabetes disease,

"Although I do many work now but I suffer diabetes long time. I have no sufficient money for taking medicine regularly and maintain the rule of daily life. I have a small shop and all time I sit down there. Sometimes it raises high level due to my unaware attitudes".

In the slum areas older people suffer from communicable diseases due to unsafe water and unclean environment, like skin diseases, fever, cough and cold, diarrhea, jaundice and dysentery. The study also shows that these common diseases attract older people. One of the focus group participants mentioned,

"Most of the time I suffer diarrhea and dysentery due to insufficient pure drinking water, I have asthma and it gives pain strongly. In my leg some skin diseases at now".

Another FG female participant shared her experience,

"In our colony, most of the people suffer diarrhea and dysentery, jaundice for unclean water. I have dysentery problem and frequently I suffer this due to water and unclean environment and problem of damaged latrine. Last time, it was a miserable for me because as long ten days it was not cured". 
Skin Diseases is common in slum older people. From the findings it was found that about all older people suffered skin diseases one or many times. One 63 years old female participant shared her view in the following way:

"I have been suffering khuja and gha (skin diseases) in my foot figure two months. It increases in night and then Ifeel miserable pain in my leg. Although I use antiseptics cream but it does not remove".

The data shows that sudden dramatic deterioration of a regular health problem is considered severe. For instance, if someone who has chronically experienced a feeling of unwellness suddenly falls. One respondent said,

"I suffer eye problem from about two years and took a operation but its problem increase now. I cannot watch properly night. I suffer heart disease and energy loses".

\subsection{Treatment Experiences of the Respondents}

Treatment and health care is essential for older people. Most of the slum older people take treatment from M.A.G. Osmani Medical College Hospital and Ragib-Rabeya Hospital Sylhet. Health and social care are necessary for older people for their better health. Most of the slum older people go to quack doctor or kabiraj for diseases. They have insufficient money for proper treatment, so, they cannot take proper medicine for remedy. One 75 years female participant shared her view,

"I have received two operations in my eye (chani operation) and before ten years ago I received operation for belly problem. Regularly, I take medicine for my heart problem. I suffer pain in my knee and backbone and take vitamin tablet/medicine for getting power. But for sufficient money I cannot take proper nutritious food and full course medicine".

The mobility and accessibility of older people are also critical. Especially for older women, a cultural stigma is attached to visiting a male doctor who is not directly a family member. In such cases, even if it is possible to take the doctor to the patient, that is not always an option for the older women patients. One female participant mentioned,

"When I suffer asthma and other diseases then I cannot visit to doctor for cultural and social stigma. Sometimes I and my daughter-in-law visit kabiraj for tabiz and pani para. Only one time I visited Osmani Hospital for treatment and admitted there about six days. Now I take medicine regularly for healer and asthma".

In general, cost flexibility by the health care provider is the most important factor. The slum older people do not want to go specialized doctor for high cost. Most of the slum older people live with extreme poverty and depend on their sons. So, a service provider who is flexible about the treatment cost and payment options is more attractive to the respondent than others who take large amount. Most of the time they visit pharmacy and quack doctor. One 71 years male respondent shared his opinion,

"When we suffer any diseases we go to pharmacy/village doctor for medicine and treatment. I like him (village doctor) because he is flexible with us. If we pay small amount he accept it. He understands poor people's problems and also gives good medicine. We always go to him and he is our regular doctor (village doctor). He is available whenever we need him, day or night he also comes to our home when needed. We are happy with him".

In addition, the study findings point out that in the old stage most people suffer some diseases because of the loss of their energy and organs of body do not function properly. This study reveals that majority of slum older people suffer communicable and non- communicable disease and take treatment from kabiraj or village doctor mostly. They need proper treatment and care for living. One participant included,

"Regularly, I take medicine for my heart problem. I suffer pain in my chest and backbone and take vitamin tablet/ medicine for getting power. Sometimes I go to Kabiraj for treatment and advices with my daughter-in-law”.

\subsection{Facing Problems during Treatment}

The research finding demonstrates that most of the older people face problem during treatment from government hospital. The slum older people have no sufficient knowledge and information from how and where they can get proper health care services. Both the interview and FG data suggest that the 
participants feel that they do not get respect and importance from the doctors. Although older people should be gotten free treatment and medicine from government and non-government hospital like Osmani Medical College Hospital, General Hospital and Ragib-Rabeya Hospital in Sylhet City, but the slum older people do not get properly due to lack of sufficient facilities. Most of the time hospital doctors referred them to private chambers. One participant shares his experience:

"I don't get proper treatment from hospital because the doctors do not treat us carely. The hospital doctors tell us for visiting private clinic and chamber. I can't visit there due to large amount of money as fee."

The study demonstrates that there are perceived feelings of discrimination and negligence among slum older people. The FG data also suggest that in the hospital sometimes patients are given wrong treatment due to negligence and less importance or delay in proper diagnosis of the disease. The facilities of the government hospital are not sufficient for huge number of patients. One 63 years female FG participant shares her experience:

"When I was ill due to my TB disease then I admitted in Osmani Medical College Hospital for proper treatment. I got admission in three number wards and this ward was crowded with female patients and only two time doctors' visit, but they did not give proper time for caring the huge patients. Although patients are many but the numbers of bed are not sufficient".

Another participant expresses his view:

"In the hospital the authority does not give importance the older people until the conditions go much worse. The nurse does not take care properly and provide medicine in time. Sometimes they misbehave with patients".

\subsection{The Health Seeking Behavior of the Respondents}

Even though they are residents of Sylhet, many slum older people are out of modern health facilities within the city. Because public, private health services are not always affordable for the extreme poor older people of slum areas and lack of awareness sometimes unable to properly utilize services. Low literacy levels, in particular, among urban slum health care. Due to these limitations on access and affordability, conditions meant that they were more likely to become ill, many visited other, less effective, service providers. Slums situated on public land also usually lacked public services such as health, water supply, sanitation, electricity and cooking gas facilities. Although some NGOs provide some health care services but these are not sufficient and proper for those older people in slums area.

Because more effective sources of treatment were more expensive, and because of bad experiences in government hospitals, many extremely poor slum older people first sought treatment from cheaper or free traditional healers (kabiraj), from other religious people or religious places such as a maazar. Traditional healers were most commonly approached in cases related to dysentery, diarrhoea, fever, cough, typhoid, and other skin diseases. Seeking support from traditional healers like kabiraj or religious persons (Imam) through enchanted water (pani pora) or an amulet (tabeej), were thought to be best option to overcome diseases caused by evil spirits. Such interventions were damaging not only because they were ineffective, and sometimes directly harmful, but also because their use delayed treatment from proper health services. The wasted time lead to greater damage and higher costs when illness was finally properly diagnosed. One respondent pointed out like,

"When I suffer dysentery and diarrhea my wife takes pani para from kabiraj and I take these for remedy".

Another FG male participant shared his experiences,

"Most of the time I visit kabiraj for my diseases because doctors don't give proper treatment and medicine. In our slum, most of the older people visit kabiraj for any diseases for cheper cost and have no side effect".

The interview data also demonstrate that most of the participants face major troubles when they suffer diseases and fell illness and go to government hospital such as Osmani Hospital for treatment. One participant said, 
"When I or my family members attack some diseases then we go to Osmani Or Ragib-Rabeya Hospital for better treatment but we understand thses doctor do not treat us properly. Sometimes we stand long time for ticket and doctor. We have no capacity for buying modern costly medicine. So, we visit kabiraj for cheaper treatment and medicine".

A number of focus group participants discussed about diseases and treatment they receive from hospital and kabiraj or other quack doctor for their treatment in old age. One participant included,

"Most of the time I suffer dysentery, diarrhoea, fever, cough, and other skin diseases and my wife go Pharmacy and Kabiraj for medicine and pani para. I cannot go hospital for my energy lose and eye problem and insufficient money for treatment. In slums area these types of diseases are common and most of the people go Kabiraj and Imam. But I received an operation in my eye from Osmani Hospital free of cost".

Slum is a place where lower income people live densely and crowded. Slums people do not get pure drinking water, health care facilities and nutritional food. Most of the slum people earn insufficient for their large number of family member. The environments of slum areas are not suitable for older people. Older people are the most vulnerable in slum areas. Health care practices and health seeking behaviour of slum people are not modern. They believe some black magic and go to quack doctor and kabiraj for treatment. Sometimes NGOs and GOs organizations arrange free health care campaign for slums people. In Sylhet city a huge number of slums and most of the poor migrated people who came Sylhet for work live in slum or colony in a lower cost. One participant shares his view,

"I do not like slum for living. I want to go to my village where I can live fresh environment and gossip with my neighbors. Here noise is very high and lack of pure drinking water. I see many people suffer diarrhea, cholera, and other diseases due to water and air. For treatment I go to hospital but sometimes my son's wife takes me kabiraj for weakness".

Another 66 years old male participant shared his experiences,

"I believe kabiraj and Imam can reduce diseases because they are the well known of our diseases and take cheaper cost. When we suffer any disease and mental problems we firstly visit Imam for pani pora because it occurs some black magic".

\subsection{Mental Health Status of the Respondents}

The study finding demonstrates that older peoples' mental health has been affected due to their diseases and present health conditions. However the degree and amount of illness vary from a wide range of conditions. The common forms of mental problems include disturbances of sound sleep, stress, depression, anxiety, weakness or loss of memory, anger and aggressiveness towards others. One female participant shared her experiences:

"Sometimes I feel alone and suffer depression because all family members go to outside of home for work and I stay alone. Sometimes I feel anxiety for my diseases and other family members for their safely return home".

Another participant with cancer shares her experience:

"Most of the time I feel anger with my daughter-in-law for my care. I behave aggressively with her because she do not take care me properly. I like my grandchild and gossip with him".

Another participant with asthma shares her experience:

"When I stay alone, I think why Allah gave me this disease. I can't stay free from tension and anxiety. All time I talk alone and community people neglect me and say I am mental patients".

\subsection{Informal Care by the Family Members}

The study reveals that majority of the older people in slum areas prefer to get care from family members because they feel comfortable in family and family members are well known about their conditions. One 69 years old female interview participant shared her view in the following way,

"Most of the time I stay alone at home because my son and daughter-in-law work out side home due to work. When I suffer any disease then I request my son to stay home and buy medicine from pharmacy and take care me. Although my daughter-in-law quarrel sometimes with me for my 
diseases and disability to do anything but most of the time she help me for my daily work. I feel comfortable in home instead of hospital and other place".

The study data demonstrated that the family members, relatives, friends and neighbors provide the bulk of the support of the older people who require assistance. Such informal support is more cost effective and satisfying to the older people than the public support systems, which are often not accessible to the poor. One 71 years female interview participant stated her experiences,

"When I admitted in the Osmani Hospital then my son could not pay the all cost of operation and medicine. My daughter's husband helped my son for paying the cost of hospital and buying fruit and medicine. Our neighbor helped me through collecting money from all slum household in this slum. Sometimes I call neighbors for emergency situation when my son does not stay home".

Another FG female participant shared her view,

"In our slum we are mostly familiar with one another and we need help then we try to help one another. Previous year when Ifelt headache and pain in my chest and shoulder then next door neighbor took me hospital as soon as possible. If he did not take me then I would die. When Ineed money for medicine then my son and daughter help me as possible as their affords".

The study findings suggested that sometimes most of the older people are maltreated within family due to their vulnerability and inability to do something. They are not given importance of decision making in family matter and other issues. One 66 years old male interview participant shared his experiences. One 75 years female interview participant said about maltreatment in family,

"My daughter-in-law quarrels everyday with me and in family, everybody treats me as a burden. My grandchildren also quarrel with me about food and cloth. Although I do many works at home, like cleaning and washing and caring of my grand children but I can't achieve respect of them. Sometimes my son says that I am a burden for him as he has to spend some money for my medical treatment".

\section{RECOMMENDATIONS}

The existing services are quietly inadequate and insufficient. Older people are increasing in an alarming rate day by day. If we don't take initiatives, it would be more complicated and fatalistic. Insufficient and disorganization in the health care services, social prejudice and beliefs, social structure and system, negative attitude towards older people are also intensifying their problems. The widespread poverty of people in Bangladesh is well documented and those with health care practices of older people in slum areas are at the risk of being the poorest of the poor. In order to make easier the life of the older people in slum areas in Bangladesh some initiatives should be taken.

According to the findings of the study, the recommendations that may be put forward in this regard are as follows:

- Social security providers should recognize that existing levels of benefit fail to protect people from poverty and would increase the risk of exclusion and abuse. Benefit services recognize the disproportionate disadvantage experienced by older people in slum areas and should be redesigned to address this poverty, marginalization and exclusion.

- Measures should be taken to make the process of accessing services and benefits easier and more responsive.

- The amount of benefit should be provided in an appropriate way to cover the personalized expenses of the benefit recipients. Home care services are an important ingredient to reduce the pain and difficulties of older people with health care practices in slum areas.

- Community care services should be expanded to care for the older people.

- Effective initiatives should be taken to remove prejudice from community and changed negative attitudes of the community people towards older people.

- Micro-health insurance for poor older people, and especially the extreme poor, may be one of the better options towards ensuring the adequate health care. 
- Government should take some programs for making them involvement through using their inner potentialities and experiences to reduce their mental suffering resulting from loneliness and isolation.

- The amount of old age allowance e and beneficiaries should be increased at satisfactory level.

- The government has to take necessary actions to the problem of poor housing in slums and squatters.

- Various GOs and NGOs engaged in slum development activities need to take steps for wider literacy and health care programme in order to accelerate improvement in annual income.

\section{CONCLUSION}

The older people in slum areas face difficulty to meet their physiological, psychological and social needs. They are mostly vulnerable in terms of living arrangement, food consumption and possessions on wealth, participation in decision making of the family and social attitude and values. In the slum areas older people are more vulnerable due to the extreme poverty, social alienation and myth and negligence behavior from the family members, exclusion from income generating activities and lack of safety network. In the slum areas in Sylhet City, most of the families live below the poverty line. These poor families are unable to meet the basic needs and health care services of older people. Most of the older people suffer from one or more diseases and they can't take proper treatment due to insufficient resources and income. The slum older people in Sylhet City generally take treatment from M.A.G. Osmani Medical College Hospital and Ragib-Rabeya Medical College Hospital Sylhet. Due to higher cost of modern treatment they mostly visit kabiraj for cheaper treatment. Slum older people are not aware about their health care practices, hygiene and sanitation and rights. So, a universal agreement is essential among the policy makers regarding the old age issues like health care services, basic rights, social security and psychological status of older people. Older people should be prepared early in life, both psychologically and socially, to face the consequences of longer life expectancy. The media should assist by presenting positive images of older people, particularly emphasizing the need for respect because of their past and continuing contributions to society.

\section{ACKNOWLEDGEMENTS}

All praises and pride are for the Almighty God, Who enabled the authors to complete this research work. The authors also express their heartfelt gratitude, profound respect, grateful appreciation to Professor Ms. Amina Pervin, Dr. Faisal Ahmmed and profound respect to honorable all teachers Department of Social Work, Shahjalal University of Science \& Tecnology, Sylhet, for their generous guidance and precious advice for successful completion of the research work and preparation of the article. The authors very much grateful to Zubaryul Hassan, Sobroto Das, Shahin Ahmed and others for their special care during the study period. The authors sincerely gratitude to the respondents and their family members who provided him important and relevant information about themselves to complete this research successfully. All the above the authors feel proud to express his boundless gratitude to their beloved parents who have been constant source of sacrifice, inspiration, encouragement and good wishes for his higher study

\section{REFERENCES}

[1] Hossain I., Akhtar T., Uddin T., The Elderly Care Services and their Current Situation in Bangladesh: An Understanding from Theoretical Perspective. J. Med. Sci., 6 (2), PP.131- 138 (2006).

[2] Kabir H., Local level policy development to deal with the consequences of population aging in Bangladesh. United Nations, 1994. PP. 33.

[3] Rahman M. M., Health Status and Health Needs among the Aged Population in Chapai Nawabganj District of Bangladesh, Indian Journal of Gerontology, Vol. 23, No. 1. PP. 32 - 41 (2009).

[4] Amirun N. M., Haque M. E., Siddiqua N. M. R. and Haque M. I., Social Status of Elderly People in Health Perspective: A Comparison of Rural and Urban Area: OSR Journal Of Humanities And Social Science (IOSR-JHSS) Volume 18, Issue 6, PP. $83-94$ (2013). 
Health Care Practices of Older People in Sylhet: A Study Conducted in Slum Areas of Sylhet City of Bangladesh

[5] National Institute of Population Research and Training (NIPORT), Mitra and Associates and Macro International (2009). Bangladesh Demographic and Health Survey 2007, National Institute of Population Research and Training (NIPORT), Mitra and Associates, Dhaka and Macro International, Calverton, Maryland, USA.

[6] The Constitution of the People's Republic of Bangladesh (As modified up to 17 May 2004), Available from: http://www.pmo.gov.bd/constitution/, [Accessed on 12 May 2014].

[7] Majumdar, Pal P., and Begum S., The Old Age Allowance for the Elderly Poor in Bangladesh: A Review, The Bangladesh Institute of Development Studies, Dhaka (2001).

[8] Comple L., M. D. and Goetz J. P., Problems of reliability and validity in ethnographic research. Review of Educational Research, 52 (no 1): 31-60 (1982).

[9] Seltiz, C., Wrightsman L. C. and Cook, W. S., Research methods in social relations. 3rd edition. New York: Holt Rinehart \& Winston (1976).

[10] Denzin N. K. and Lincoln Y. S., Handbook of Qualitative Research, $2^{\text {nd }}$ edition, Thousand Oaks, CA: Sage (2003). 